\title{
Orléans (Loiret), crypte de Saint-Aignan
}

\section{Chantal Arnaud et Pierre Martin}

\section{(2) OpenEdition}

\section{Journals}

\section{Édition électronique}

URL : https://journals.openedition.org/cem/885

DOI : 10.4000/cem.885

ISSN : 1954-3093

Éditeur

Centre d'études médiévales Saint-Germain d'Auxerre

Édition imprimée

Date de publication : 15 août 2004

ISSN : 1623-5770

\section{Référence électronique}

Chantal Arnaud et Pierre Martin, « Orléans (Loiret), crypte de Saint-Aignan », Bulletin du centre d'études médiévales d'Auxerre | BUCEMA [En ligne], 8 | 2004, mis en ligne le 13 décembre 2006, consulté le 22 septembre 2022. URL : http://journals.openedition.org/cem/885 ; DOI : https://doi.org/10.4000/cem. 885

Ce document a été généré automatiquement le 22 septembre 2022.

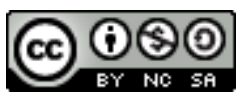

Creative Commons - Attribution - Pas d'Utilisation Commerciale - Partage dans les Mêmes Conditions 4.0 International - CC BY-NC-SA 4.0

https://creativecommons.org/licenses/by-nc-sa/4.0/ 


\title{
Orléans (Loiret), crypte de Saint- Aignan
}

\author{
Chantal Arnaud et Pierre Martin
}

1 L'église Saint-Aignan d'Orléans doit son origine à la sépulture du saint évêque mort en 453, inhumé dans une nécropole à l'extérieur de la ville antique. La sépulture du saint évêque est dès le $\mathrm{VI}^{\mathrm{e}}$ siècle recouverte d'une basilique. Une communauté y est attestée au milieu du VII ${ }^{\mathrm{e}}$ siècle. Les moines sont remplacés par des chanoines au $\mathrm{IX}^{\mathrm{e}}$ siècle. Durant le premier tiers du $\mathrm{XI}^{\mathrm{e}}$ siècle, l'édifice est entièrement reconstruit à l'initiative de Robert le Pieux (consécration en 1029 ; travaux à la couverture en 1031). Après les guerres des $\mathrm{XIV}^{\mathrm{e}}$ et $\mathrm{XV}^{\mathrm{e}}$ siècles où elle fut détruite, l'église haute est reconstruite à partir de 1438.

2 La crypte de l'église Saint-Aignan d'Orléans, édifiée au début du XI ${ }^{\mathrm{e}}$ siècle, est l'objet d'études universitaires menées par Pierre Martin (université de Poitiers). Le site est également intégré au projet collectif de recherche sur les "Matériaux, techniques de construction et datation entre Loire et Saône autour de l'an Mil” (CEM). C'est pourquoi, dans la continuité d'une première campagne de relevés en 2002, il a semblé nécessaire d'associer à la poursuite de l'étude du bâti dans le couloir sud une nouvelle analyse d'un sondage réalisé en 1954 et laissé ouvert depuis lors (Lesueur, 1957).

3 L'opération ${ }^{1}$ a permis de constater que le couloir a été aménagé sur un espace en partie occupé par plusieurs constructions, dont on ignore l'état et les fonctions lors de la mise en chantier de la collégiale au début $\mathrm{du} \mathrm{XI}^{\mathrm{e}}$ siècle (en revanche, il n'a pas été reconnu de sépultures). Le mobilier associé permet de remonter aux premiers siècles après JésusChrist (monnaie, mosaïque...).

4 La première phase de travaux correspondant à l'édifice en élévation est la construction de la salle occidentale - le martyrium - et du mur nord du couloir. Les fondations prennent en compte l'état du sous-sol. À l'est, aucune maçonnerie antérieure n'a été remarquée ; le mur repose sur un important massif de fondation qui a été creusé dans le sol naturel. À l'ouest, le mur se colle aux importantes maçonneries antérieures. Dans les deux cas, il faut remarquer que le soin apporté aux fondations visait à assurer la meilleure stabilité 
possible à un monument auquel le contrebutement naturel au sud faisait défaut en raison de la déclivité du coteau.

5 Le mur nord du couloir se caractérise par l'emploi d'un appareil allongé. Il présente un ressaut vertical à une distance de 9,30 $\mathrm{m}$ de l'entrée. Ensuite, le mur a été plusieurs fois remanié et on note des appareils très différents.

6 L'étude des mortiers et de l'appareil allongé de cette première section demeure intéressante. Dans la partie est, la base du mur est liée au mortier de tuileau (sur trois assises) alors que les assises supérieures sont liées par un mortier également rose mais en raison de la présence de granit. On ne note aucune différence dans l'appareil allongé. Les fondations, composées de blocs divers, sont liées par un mortier plus ocre. À l'ouest, on constate un changement de direction des assises, qui correspond à l'apparition de maçonneries antérieures ; l'appareil offre alors une taille moins soignée et les pierres sont liées par un mortier ocre (identique à celui des fondations sises à l'est). On peut donc supposer qu'il y ait un emploi spécifique des différents types de mortiers en fonction de leur rôle dans l'édifice.

7 La pile appareillée située à l'angle sud-est du couloir et l'arc fourré qu'elle supporte ont été mis en place dans un deuxième temps. La fondation de la pile vient s'appuyer sur celle du mur nord et l'arc repose sur ce dernier ; le mortier employé, gris-blanc, diffère nettement de la première phase. Dès lors, il convient de savoir si le transept était prévu à l'origine ou si on a ici la preuve d'un repentir.

8 C'est dans une troisième phase que le reste du mur sud fut construit : cette maçonnerie de moellons vient buter contre la pile d'entrée. Un sondage pratiqué par le Dr Lesueur à la jonction de ces deux structures a également révélé la présence, à l'arrière, d'un parement plaqué lui aussi à la pile mais néanmoins antérieur au mur de moellons. Ce dernier, très peu fondé, repose sur les remblais de fondation du mur nord. Le couloir est alors couvert par un berceau plein cintre sur une longueur de 6,50 m environ (entrée comprise).

9 Dans la seconde moitié du couloir, on ne sait rien pour le moment des dispositions du $\mathrm{XI}^{\mathrm{e}}$ siècle car les maçonneries observées au nord comme au sud appartiennent à des phases postérieures de réaménagement : abaissement du niveau de circulation dans la partie occidentale, reprises de plusieurs sections de la voûte, aménagement d'ouvertures et application d'un enduit couvrant largement les surfaces et les rendant en grande partie illisibles.

Une demande de fouille programmée a été faite pour 2004 afin de pouvoir poursuivre cette étude et tenter de répondre aux questions que cette première investigation a permis de poser. 


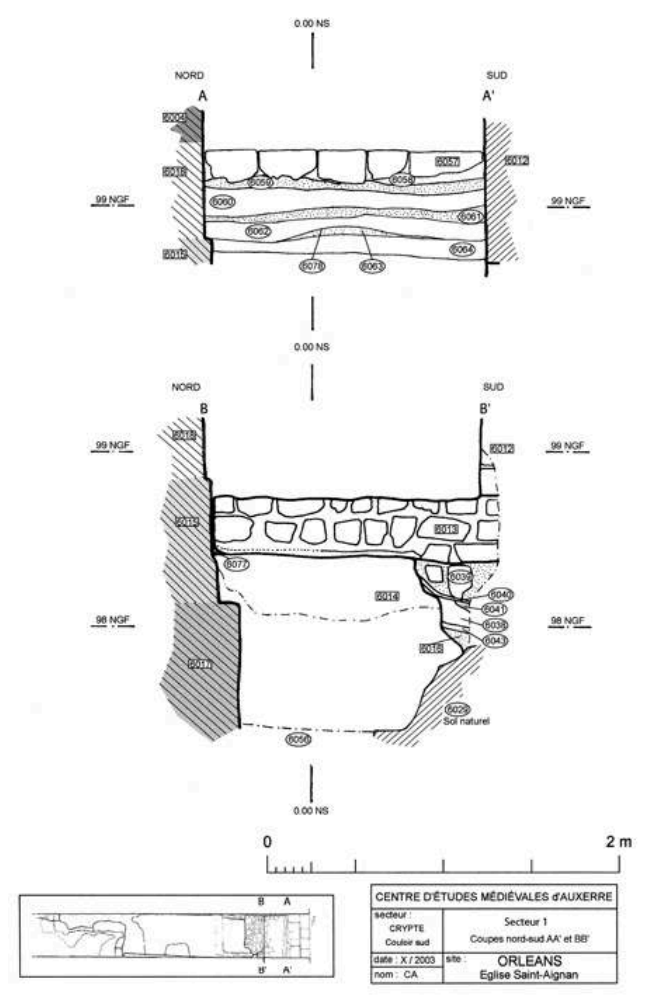

Orléans, église Saint-Aignan. Crypte, couloir sud, secteur 1, coupes N/S (C. Arnaud - CEM)

\section{BIBLIOGRAPHIE}

LESUEUR Fr., "Saint-Aignan d'Orléans, l'église de Robert le Pieux", Bulletin monumental, t. CXV, 1957, p. 169-206.

MARTIN P. et ARNAUD Ch., Orléans (Loiret) - Crypte de Saint-Aignan. Le couloir sud (section orientale), Rapport d'intervention archéologique, CEM-SRA, Orléans, 2003.

MARTIN P., Orléans (Loiret) - Crypte de Saint-Aignan. Le déambulatoire et les chapelles rayonnantes, Rapport d'opération d'archéologie du bâti, DRAC, Orléans, 2002.

OTTAWAY J., “Collégiale Saint-Aignan", in Barral i Altet (X.) (dir.), Le paysage monumental de la France autour de l'an mil, Paris, 1987, p. 257-258.

RousSEAu P., "La crypte de l'église Saint-Aignan d'Orléans", in Louis (R.) (dir.), Études ligériennes d'histoire et d'archéologie médiévales, Auxerre, 1975 (Mémoires et études présentés à la semaine d'études médiévales de Saint-Benoît-sur-Loire du 3 au 10 juillet 1969), p. 454-473.

VERGNOLLE É., "Saint-Aignan d'Orléans", in Saint-Benoît-sur-Loire et la sculpture du XI' siècle, Paris, 1985, p. 141-152. 
NOTES

1. Opération sous la responsabilité de Pierre Martin, avec la collaboration de Chantal Arnaud.

INDEX

Mots-clés : crypte, Aignan (saint), Saint-Aignan d'Orléans

Index géographique : France/Orléans 